\title{
Love is in the air (rotor)
}

S Hancocks, OBE*

\section{Falling in love, or being in love, at work is not the easiest of situations and working in a dental practice makes it less easy still.}

At this point of the year with the harbingers of Spring poking their little green shoots above the winter mulch, a young man's fancy turns to...well what exactly is it that it turns to? And in any event that was presumably before the days of equality, diversity and cross-representational gender accommodation so now it would be political correctly expressed as 'a young gender-neutral person's fancy turns to...', which, forgive me, does I think rather negate the whole point of what it was the fancy was about to turn to. But let's move on regardless and accept the wisdom that's been handed down to us. For sure, as we land on 14 February the good Saint Valentine will be looking on with a merry smirk as the sap rises, the crocuses peek out and that host of Wordsworth-like daffs promises new life and warmer times.

But how does such frisky chemistry enmesh the dental team, for doubtless we are not so inured from the vagaries of hormonal mediation that we too are unaffected by the fluffy bunny of fancy? The trouble is that we're different. Of course we are. For a start we're professionals and as such are brought up specifically not to show our feelings, and certainly not to patients and fellow professionals.

We are also at something of a further handicap in that the British so consistently confuse love with sex, about the very suggestion of which we famously blush and titter, and apparently to which we regularly say 'no'. The sublime awkwardness is not helped in the confines of the surgery where the patient ends up completely supine (hardly the least suggestive position) with their head in the operator's lap. Uh huh. Had we been practising using such fully reclining chairs in the heyday of the Carry On films the imagination knows no bounds as to what the likes of Kenneth Williams, Barbara Windsor and Sid James would have made of it. Although I'm sure there would have been an 'Oh matron!' line smuggled in somewhere.

In the matter of affairs of the heart, any sort of 'relations' with patients are entirely out of the question. Or are they? Where stands the ethics on this one now? In the 'old days' such things were certainly frowned upon and many is the smoky taproom tale of the GDC passion police patrolling outside suspect dental surgeries at dusk on the off-chance of catching a young dentist whose fancy had turned to, well, what ever it is that a young dentist's fancy does turn to that the Wimpolean sleuths were attempting to quash.

This entirely leaves aside the slightly nauseous situation of star-crossed lovers visiting the practice, for whatever reason; one accompanying the other for that full mutual support that love's young dream demands or both attending together as they can't bear to be out of each other's sight for longer than a quick amalgam.
Their canoodling in the waiting room is so tiresome and does the practice no favours at all in terms of attracting new patients. Rather like spotting a love bite on patient's neck just as you're about to discuss a complex treatment plan, it plays havoc with the concentration. To paraphrase Alan Bennett, it's the sort of thing one expects under the NHS but not in private practice.

Not that falling in love with work colleagues is any the less traumatic to those around. Invariably it's great fun in the runup. Everyone delights in the speculation and gossip about so-and-so and what's-hisface getting it together, how they're trying their best to cover it up but failing pathetically to do so, how they were seen here and spotted there and caught somewhere else (usually the dark room - it really is no surprise that computer assisted imaging isn't catching on as fast as logic dictates...when a

\section{The sublime awkwardness is not helped in the confines of the surgery where the patient ends up completely supine (hardly the least suggestive position)...}

young man's fancy turns to digital imaging....be completely honest, it doesn't have the same feel does it?). Then there's the 'outing', when the couple in question 'just can't hide it any longer' - like we've ALL known for weeks anyway but act astonished so as not to spoil their moment of triumph. Then the honeymoon period (not talking weddings you understand, just the 'buying ready meals together for the evening in' stage) when as far as the rest of us are concerned it all becomes really rather dreary and pedestrian before the really good 'regret phase' takes a hold. Slammed doors, furtive whispering in corners, smudged mascara, dramas, grumpy looks, dinners for one again. Normality. Marvellous.

I well remember the couple that met during our first week at dental school and fell desperately in love. Gazing into each other's souls they carved up their cadaver in anatomy classes apparently without another thought for that in which they were actually engaged, passing each other scalpels and manuals with a starry-eyed abstraction. The rest of us meanwhile queasily identified the various veins, nodes and organs that we'd managed to hack out of the corpse before us and nodded and winked half disbelieving and half jealous. Of course it didn't last. How could it? By the time we'd got as far as the GI system in week three they'd asked for transfers to separate bodies and to the best of anyone's knowledge never shared another gall bladder again.

Still, take comfort, with customer care going the way it is, it can only be a matter of time before some marketing guru comes up with the 'dating practice' - botox, bleaching and...really, what is it that a young man's fancy turns to?

Stephen Hancocks is Commissioning Editor of the BDJ 